\title{
Correction to: Reluctantly Solo? Representations of Single Mothers via Donor Procedure, Insemination and IVF in Swedish Newspapers
}

\author{
Helena Wahlström Henriksson and Disa Bergnehr
}

\section{Correction to:}

Chapter 11 in: B. Åström and D. Bergnehr (eds.), Single Parents, Palgrave Macmillan Studies in Family and Intimate Life, https://doi.org/10.1007/978-3-030-71311-9_11

The original version of Chapter 11 was inadvertently published as nonopen access. It has now been changed to open access under a CC BY 4.0 license, and the copyright holder has been updated to 'The Author(s)'. The correction to the chapter has been updated with the changes.

The updated version of this chapter can be found at https://doi.org/10.1007/978-3-030-71311-9_11

(C) The Author(s), under exclusive license to Springer Nature 